\title{
Clinical Observations Body System or Organ Class
}

National Cancer Institute

\section{Source}

National Cancer Institute. Clinical Observations Body System or Organ Class. NCI

Thesaurus. Code C119796.

The body system or organ class associated with a clinical observation. 